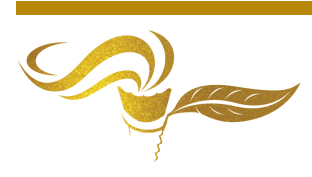

\title{
Scholasticism with a Transdisciplinary Attitude
}

\section{Paul Gibbs}

Emeritus Professor, Middlesex University, London, UK

Received 16 September, 2021; Revised 19 October, 2021; October 20, 2021

Available online October 20, 2021 at www.atlas-journal.org, doi: 10.22545/2021/00161

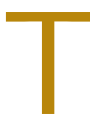

his paper considers how we might understand Nicolescu's transdisciplinary approach to being in the world through a scholastic metaphysics, to ground Nicolescu's ontology in a different historic epoch. By way of interpretation, I want to suggest that Nicolescu's three axioms of multiple levels of reality, the hidden third and the logic of the included middle emergent in complexity can be enriched by Duns Scotus' notion of univocity and formal distinction. Patterning together, they offer a metaphysics basis of transdisciplinarity which is not reliant on a scientific rationality for its feasibility (nor being in competition with such a deconstructing position) through the rigour of the scholastic method. It takes as it focus the idea of a transdisciplinary attitude and suggests that Scotist realism, and scholasticism more generally, could provide an illuming way of viewing a transdisciplinary educational project. This is a speculative paper is about being, potentiality and the framing of being within the paradigm of metaphysical scholasticism inspired by the transdisciplinary maxims axioms of Nicolescu ${ }^{1}$ For an excellent discussion of Nicolecsu's vision and that of others in the field of transdisciplinarity, see McGregor, 2015) [3].

Keywords: Nicolescu, Duns Scotus, Transdisciplinarity, scholasticism, Scotist realism, mastery.

\section{Introduction}

The metaphysics and cosmology of transdisciplinarity owe much to Professor Nicolescu and the use of analogies he makes to the physical world of physics. Indeed, this approach is grounded in the works of physicists and philosophers; Walter Thirring, Werner Heisenberg, and Stéphane Lupasco upon which Nicolescu calls as inspirations for his own work. This reliance I believe might be problematic and I attempt to approach transdisciplinarity from a different metaphysical perspective, through the thoughts developed by Duns Scotus and the notion of emergence. This approach, which essentially combines the transcendent and the immanent in a common sense way, provides an alternative metaphysic for consideration.

\section{Transdisciplinary Attitude to Being}

The Charter of Transdisciplinarity (de Freitas et al. 1994) identified a number of fundamental characteristics critical for the cultivation of a transdisciplinary attitude and vision among individuals, the most significant being in Article 14:

\footnotetext{
${ }^{1}$ The axioms were first formally discussed in Nicolescu's Nous, la particule et le monde [2]
} 
Rigor, openness, and tolerance are the fundamental characteristics of the transdisciplinary attitude and vision. Rigor in argument, taking into account all existing data, is the best defence against possible distortions. Openness involves an acceptance of the unknown, the unexpected and the unforeseeable. Tolerance implies acknowledging the right to ideas and truths opposed to our own. (The Charter of Transdisciplinarity, 1994) [1].

The argument is premised upon transdisciplinarity's actuality, as an authentic and appropriate way of exploring the unity of Being ${ }^{2}$ and creating immanent knowledge of the forms of being within and across different realities and in transcendence. I caution myself not to make brute distinctions here. Transcendence will not mean to entirely escape or sublimate the immanent nor do I want to use immanence to altogether seal and close off the horizon of transcendence. In transcendence and immanence, we find a doubled presence of worldliness and universality. This contextualises disciplinary epistemologies as offering necessary, but not sufficient, revealing of realities in which being and its forms can be understood essentially as well as existentially. What is important to this argument is a contemporary understanding of scholasticism emergent from the medieval philosophers such as Duns Scotus ${ }^{3}$ and summarised by Feser, 2014 [4] to offer a non-scientism base for the discussion of a transdisciplinary reality and our being as part of that world. Since emergence is an important feature of human life, all knowledge development which is concerned with human beings and their activities in the world might, I will argue, be derived from a transdisciplinary metaphysic contingent on causal powers. This is not, and is it certainly not my intention, to assert that casual powers are in direct competition with the empirical science and its claims of truth and knowledge known through experience. I do however distinguish transdisciplinarity from interdisciplinary (like Scott, 2017 [5]) on the basis of the emergence of realities to those of complexity. This occurs where outcomes cannot be generated by the additive pooling of the knowledges of the various disciplines concerned, and "requires a whole integration, or genuine transdisciplinarity" (Scott, 2017: 40) [5].

This idea settles transdisciplinarity as an exploration of ontology rather than a distinctive epistemological method and offers an alternative to disciplines' hegemony of verifiers of knowledge. In this sense transdisciplinary as a metaphorical tool; a catalyst, with a teleology ideology for change. The inherent difficulties of such models are the experience of a multiplicity of realities which are neither laminated nor fixed but flow rhythmically under the influence of complexity and intra-reality causation, yet deny causation between realities. The rhythm of realities forms an open system in which possible worlds emerge and realities are (a) perceived as independent yet indeterminate and (b) realised and dependent on the location of the becoming being. To view these open systems in which becoming is the realisation as potentiality, (both internally natural and external elicited) as energy and power that enables the capacity to bring about change in another thing or in itself aligns with Aristotle's fourth and final cause.

I begin by considering the singularity of our being, then take the three core issues of a transdisciplinary attitude; rigour, openness and tolerance, looking at them separately, and then propose a form of character education which might include all. Moreover, what is important to this argument is a contemporary understanding of scholasticism emergent from the medieval philosophers such as Duns Scotus ${ }^{3}$ and summarised by Feser, 2014 [4] to offer a non-scientism base for the discussion of a transdisciplinary reality and our being as part of that world.

\section{Being you}

This discussion is grounded historically in Aristotle's extensive discussion of the emergence and harnessing of potential in Book $\Theta$ (Chapter 9) of his Metaphysics [6] as well as in De anima [4] and the Physics [6]. Although an extensive discussion is not warranted here ${ }^{4}$, Aristotle introduces a notion of the being of the being of a thing fixed in terms of a categorical substance, where the identity of being is able to be

\footnotetext{
${ }^{2}$ Capital B is used for Being when referring to the totality of Being; lower case for humans' being.

${ }^{3}$ Duns Scotus is used rather than other scholastics because of the development of his methodology and the subtlety of his approach as well as his key position on univocity and singularity.

${ }^{4}$ See Beere, Doing and Being, 2009 [7] for an excellent and successful rendition of such a task.
} 
"distinguished in respect of potentiality and fulfilment, and of function", (1045b: 33) [6] and its capability to become (1003a:6) [6]. For example, Jane is first a human being with a capacity (her first actuality) for knowledge, like all humans. She can develop that capacity's potentiality in many ways, one of which is to become an engineer. In realizing her nature, Jane is flourishing under those conditions that allow her to do so as herself in the form of engineer. In this sense we draw a distinction between the power and the capability for it to be actualised; the holder of the power. In a real sense it is the processor of the power which is the cause of change, not the power in and of itself. To explain the causes of a thing Aristotle divides thing into those which exist by nature and those for other reasons; artefact of life. In the former, Aristotle offers four general classes of explanation of a thing divided into four general causes; substance, form, efficient and final. (see Physics, book 2, 194b23-35. [6]). It is Aristotle's fourth cause, the formal cause, for "the sake a thing is done" (194b34 [6]) that natural thing develops towards if not encumbered by other forces. Clearly this teleological causation has potential to be ascribed to some divine plan but Aristotle discounts this argue it what the thing is.

Aristotle maintains that all things have their own nature but the elements of this nature "be elements of being not by accident but just because it is being" (1003a29-30) [6]. Yet he also maintains that there are "many senses in which a thing may be said to 'be' but they are related to one central point, one definite kind of thing" 1003a32-33/30 [6]. Tellingly, he also maintains that this Being is not a universal, for it has a primary cause itself. Indeed, Aristotle's onto-theological statements in Book VI of the Metaphysics such as "all causes must be eternal, for they are the causes of so much of the divine that appear to us" (1026a16-18 [6]) gives evidence to this. Thus Aristotle's notion of being requires eternal, transcendental causes as well as those causal powers actualised through the realisation of potentiality from which characteristics of the thing are emergent. The idea of hylomorphic form and substance underlies the following discussion.

Following Aristotle, Duns Scotus distinguishes free and self-determining causality (possibilities for being) from natural and necessary causality (mode of being) and it is the former that this paper now considers. At its essence, the questions deal with self-change and the willed possibilities this implies; a will that is the cause of its own determination. Moreover, the will is indeterminate and when it makes a positive decision of either volition or nolition which elicits a voluntarily act, it is determining itself. Such decisions require enlightenment. In context, the arguments made are the resolution of Being as univocal, for if it were not then the use of the words such as 'good' and 'wise' which apply to God give no functional guidance to humanity and allow anything to be done in God's name, for it would be impossible to understand why God acts through the language we process. We are left with divine and mortal meanings, one determinate and the other indeterminate and unintelligible to us. Being, that of God and that of humanity, would allow abuses to be undertaken in God's name with immunity. Scotus argued that the attributes of being which are those of God in essence have the same meaning when used by humanity, the attributes of God being the co-existent universals which apply equally to humanity. Blending the immanence and the transcendental is Scotus's main ontological achievement and led Deleuze to suggest that there "has only ever been one ontology, that of Duns Scotus. Which gave being a single voice" (2014:45) [8]. Thus "the concepts of being; the one, trust, and the good are all unitive contenta in the real and indivisible whole" (Wolter (1997:101 $[9])$.

This in itself does not solve the issue of universality and singularity and how Being manifests itself in difference, fundamentally asking why humans (and all other things) differ within their genus. This is central to our quest, for we want to understand firstly how we, not the other, should best flourish. We might be motivated to answer that this is a question of fate, destiny or luck. Aristotle suggests that it is the fulfilment of our potential as entelecheia, which captures what it means for a thing to be what it is; a kind of becoming-toward-itself which thus presents a purpose to the actualisation of potential, comparing it merely as an act of participation or to the full fulfilment of its potential. This acknowledges that what exists potentially is ontologically dependent on what exists actually (one must be able to become, have the capability to do so first, in order to actualise one's potential). Scotus resolves how universals ${ }^{5}$ may seem both real and distinctively logical by the process of a formal distinction. That is, there is a formal

\footnotetext{
${ }^{5}$ Consider Bates' (2010) [11] discussion of universals and the solution that enable Scotus to retain a notion of commonality which hold the thingness of things.
} 
distinction between an individual's nature and their personhood.

Scotus also suggests that to act is bounded by the powers in our choice to act, stimulated by the powers of our internal potential in relationship to external powers, and potentialities are aligned with the properties of the haeccetias ${ }^{6}$ (the thingness of a thing or the personhood of the individual) and this realistically ${ }^{7}$ determines the distinctive entity we are. It is the form of the things which distinguishes it from matter and thus universals are considered real. The formal distinction is evident according to Cross (1999) [10] between the soul and its powers of intellect and will.

Scotus conceives of the causal agency as separate from, and working upon, the causal dispositions of a thing. Yet, not all the properties or dispositions or causal powers of a thing are equally important in understanding their singularity, which gives meaning to an individual's identity, but all might contribute to the potentialities to be realised. This recognition of difference is central to the scholastically influenced ontology of Spinoza and, by inference to Deleuze ${ }^{8}$, transcendental empiricism. In both, there is a clear appropriation of Duns Scotus' univocity where immanence rather than transcendence dominates in both of their conception of Being. In the case of Spinoza it is an alternative explanation of what initiates this actualisation. He asserts that existence and its endeavour within the unified pantheistic nature of being is revealed through the multiplicity of difference. The more one is able to resist these external powers the greater is our understanding of ourselves and the more we are able to be the cause of ourselves. Spinoza calls this process conatus (The Ethics, 9VII, 1999: 109 [14]) which is our desire to cultivate the essence of oneself and the realisation of the power to do so. What this might be seems to remain problematic even for Spinoza when he claims that casual powers when activated are intent on creating the best we can. To achieve this internal causal powers engage with external powers. For Deleuze it is in the notion of difference and how to "make sense of everything as part of one and the same purely immanent reality-a reality that is free of any such absolute transcendence" (Moore, 2015: 3, [15]).

The realisation between the imaginations that stem from the imaginal realm and personal fantasies is the imaginatio vera and guidess to our self-activation. This end has to be imagined as Corbin states each of us "carries in himself the image of his own world, his Imago mundi, and project it into a more or less coherent universe, which becomes the stage on which his destiny is played our" 1990:8 [16]).This is a central concept for Nicolescu's Homo sui transcendentalis a concept within which he explores the integration of potential realities, understandings and perceptions. This is transdisciplinarity and it "opens an unlimited space of freedom, understanding, tolerance and love" (2002:74) [17].

\subsection{Willing Me}

These differences offer humanistic and egoist models of morality but before moving there I want to try to understand the complexities of a univocal ontology, the causal powers associated with it and the different realities of which it is constituted, without attracting the criticism of recidivism. At their core are the questions raised by Hoffman (1999) [18] in respect of Scotus' work: if the will is undetermined, how can it choose anything at all, and why does the will choose one possibility rather than the other? Scotus' answers might be considered incomplete in themselves, for he argues that the will, seeks and selects on possibilities and, as such, that is its purpose. What drives and energises the causal powers for Scotus is the agency of the will which determines what the intellect ponders, drives how the will and the intellect are related and thus has rational potency and so can bring about contrary possibilities. The free power of the will has both an indication for self-advantage (affactio commode) and for social justice (affactio iustitae). Scotus thus conceives of the will as working for both self-fulfilment and for justice. Moreover, if the will self-determines its activity, it follows that it is in some respects independent of exterior influences and the will's freedom is not compromised by the cooperation of the intellect as a natural cause, since the will freely chooses regarding the use it makes of this ${ }^{9}$. I suggest, based on Scotus' assertion that it is

\footnotetext{
${ }^{6}$ I base here my understating of this on question six in his Early Oxford Lecture on Individuation [12].

${ }^{7}$ The realism of the formal distinction has been contested (see Dumont , 2005 [13])

${ }^{8}$ In Twenty-Fifth Series of The Logic of Sense,[6] in Univocity Deleuze states that 'Philosophy merges with ontology, but ontology merges with the univocity of Being'

${ }^{9}$ See Hofmann1999 [18] and Wolter (1997) [9]for detailed discussions
} 
the will's inclination/affection for justice that plays an important role in enabling us to strive towards our open-minded freedom, fulfilment and self-cultivation within the priority of the natural truth of being. As Normore attributes to Scotus, "at the time of choice the agent has the power to choose a result of refrain from the choice" (2021:78) [19]. It is recognising that our nature is not above that of other entities but is in the unity with other entities. Here our relational being finds space for wonder, awe, beauty and duty in a world which renders the complex simple and which tries to resist the unexplainable.

Nicolescu offers a short chapter on rigour, openness and tolerance as core characteristics of the transdisciplinary attitude explored in the Manifesto of Transdisciplinarity (2002)[17] and I discuss these next. For Nicolescu, the first- rigour - is manifest in language, which is common to scholastic but where it differs in the sense of applying the rigour of scientific knowledge (scientism) to the metaphysics of being. However, such divergence is not evident in openness and tolerance which are premised on a non-deterministic cosmology seeking acceptance of the unknown in the context of change. So important are these characteristics that Nicolescu claims that "[r]igor, opening and tolerance must be present in transdisciplinary research and practice" (2002:22) [17]

\subsection{Rigour}

I want to discuss rigour as used in the 14 Article (above) in method and not as methodology, a distinction made by Nicolescu himself. He argues, I believe, for rigour in the development of his axiom of transdisciplinary methodology but also in the methods that emerge from them. Such a rigour is present in scholasticism applied through Scotist realism ${ }^{10}$ where the formal distinction, together with free will, are essential as a form of rigorous inquiry (Almeder, 1973) [20]. This difference, however, is in not being based on a scientism epistemology but upon a metaphysics where conceptual precision, rigorous argumentation and clarity of expression hold sway. Indeed, Pierce renders Scotus' solution of the formal distinction to the issue of universals as a methodological foundation, along with critical common-sensism, of his concept of pragmatism (Garrison, 2005) [21], showing that Scotism and thesych "creative philosophy of science are not necessarily incompatible" (Vos, 2009:396) [22]. Indeed Pierce's pragmatism cosmologically and the provisional nature of knowledge has much in common with transdisciplinarity.

Scholastic inquiry, for I want to suggest this form of inquiry offers the rigour that the transdisciplinary attitude demands. For the purposes of this paper I follow Van Asselt, and Van Asselt (2011) [23] consider that it is a method characterised by deputations which evolved over the middle Ages. The method discussed here relates predominantly to the investigation of Scotus. This is a dialectic form of enquiry, devised to seek resolution of points of view through an approach to issues of interpretation, formulated and presented by the tutors predominately in medieval universities. Very basically, it consisted of a work being present (usually a reading but more contemporarily a problem), a period of reflection followed by interrogation of readings and the authority which presented it. Following this, further investigation of existing knowledge was conducted and a series of logical arguments developed which both supported and countered the authority position we developed originally but not now as a disjunctive either or of a closed system but of possibilities. Through the necessity of logic a resolution of the contra views was agreed upon. Scholasticism can be conceived as both method and content.

The basic model was used as a teaching method in medieval universities and consisted of a lecture, read from a text, a period of reflection and then a debate on the questions that emerged from the reflection. . Over time, and certainly for Duns Scotus, the questioning or quaestor became the most important part of instruction. There were also scholarly discussions or disputations. Rouwendal (2011: 62) [25] concluded that the method settled on a four-stage process each with specific forms: 1 . A statement (status quaestionis); 2. List of arguments against one's view (objections); 3. A list of arguments from the tradition in favour of one's own view; 4. A refutation of the objections (fonts solutionum). All of these followed a rigour that focused on the questions emerging, based on what had been previously known (creating arguments that supported and denied forms or resolution of the questions. In the thirteenth century the research function of the quaestio developed into the quaestio disputata. In the case of disputations a solution was devised

\footnotetext{
${ }^{10}$ See Pierce, 1905 [24] and Almeder, 1973 [20].
} 
from the narrative of the arguments made: critically, a public discussion could be organised to discuss the problem. Once the process was concluded a resolution was determined based on all the arguments made. The instrument of the integrative process was logic. The formal structure remains in many aspects of higher education knowledge verification, especially of doctoral examination, but I want to consider this method as a narrative on problem identification and subsequent solution, developed as a transdisciplinary method.

Nicolescu's notion of the transdisciplinary method might, I would suggest, be considered a derivative of this. I make this argument based upon the engagement for a common narrative used for the discussion, a view which could be contested, and all views used to resolve a solution, done within a recognition of the transcendant and immanence. Indeed it has similarities in the contemporary approach of participatory research and analysis.

\subsection{Openness and Tolerance- it could all be so different}

If we are to be open to a world that is not created deterministically then the possibilities of difference must be central to such a metaphysic. Scotus develops the notion of synchronic contingency in his Lectura 139 , [26] arguing that, that which is, might very well be different ${ }^{11}$. In essence, that which has been actualised is just one possibility :at any point in time; other possibilities are real possibilities but have not and will not be actualised. That is to say at any moment factual reality can be different from what and how it is. If true then as Garrison suggests "logical contraction and even catachresis are a necessary to sustaining emergent, endlessly evolving, and creative universe" (2005:180) [21]. Finding this relationship of Being with being-here-for-oneself is the power of knowing oneself which has attracted significant attention through the history of the divine and the mortal tackled by Duns Scotus and Avicenna and indeed within the transdisciplinary axiom of Nicolescu's hidden third. There, the hidden third is the placeless place where the transcendental blends with the immanent and the philosophical with spiritual. To enter mundus imaginalis requires one to seek to know oneself, but with a knowledge that one does not already have. It is the precursor of embarking on self-flourishing and is available to us, as Heidegger has suggested, through meditation and poetry and in the self-reflection of Kierkegaard's moment of vision ${ }^{12}$. Our search for knowledge of how we can fulfil ourselves is a cyclical one with our return to our point of embarkation changed, more aware but still deficient. The resolution, again as Heidegger has suggested, is from the thrownness of our existence into the world and our flourishing as our true selves which is ongoing and unresolved until death.

Based on these concepts I want to argue that through the weaving and patterning of the univocity of being and its co-existent transcendentals, Duns Scotus ${ }^{13}$ opens an access to the complexity of being, highlighting and integrating immanent aspects with the transcendental. I want to suggest that how individual beings realise their own being (I want to hold fast on identity for the moment) depends on how we and they see the openness of the system in which they are located: thus, the spatial-temporal context is a determinant in the ways the causal powers actualise themselves, specifically as opposed to the perception of closed systems. The proposed causal powers are emergent in the sense that they are motivated by the situations and the right or natural timing of the disposition to the oneness of the being and this oneness is authentically revealed in the openness of our worldly systems ${ }^{14}$.

The causal powers can be differently willed and thus create different worlds for the emergent being to transact with. Each being is shaped by acting and thinking differently about the structure of individual becoming. It is also shaped through what is willed romantically and poetically in its first formation, rather

\footnotetext{
${ }^{11}$ As part of Pierce's Scotism he supports this notion in his Monist paper The Doctrine of necessity Examined (1892) [27]. Aristotle counter to his assumed binary notion of nature talks in the Metaphysics, Book $\Theta$ "that, what "is capable of being may either be or not be; the same thing, then, is capable of both being and of not being" (1050b 10) [6]. This has resonance with Nicolescu's concept of the included middle.

12 no footnote, please add.....

${ }^{13}$ Scotus allows other transcendentals which are pure perfection such as wisdom which are transcendentals for the simple reason that they can be predicated on God., (Concept and Articulation of the Transcendentals, Wolter, 1997) [9].

${ }^{14}$ There is a growing literature on system transdisciplinarity which is not addressed here but recognised.
} 
than reifying it through the logical and calculative thinking associated with disciplines and the forms of grammatical languages they employ. These powers work within our world of experiences commonly shared yet are not constrained by them, creating a new configuration of the world as an open system within which islands of closed systems function. The enframement of closed systems functions to shape our inauthenticity and lead us to deny what we might be, so as to settle for the comfort of what others require us to be and work against our flourishing. Powers that have been actualised within the open system are working creatively together with other powers, whereas in closed systems they are suppressed or counteracted to provide stability, in the form of, perhaps, a consistent identity.

The exploration of the ways these causal powers bring us into becoming what we might be in open systems do not reveal a stable identity easily labelled in packages of sameness but a fragmented and reoccurring being and provides the potential for us to understand our life project. This requires a blending of ways of knowing within the rhythms of realities, leading to potency's actualization. Perhaps this is what Deleuze [8] meant when, he suggests that the univocity of being "has three determinations: one single event for all events; one and the same aliquid (something) for that which happens and that which is said; and one and the same Being for the impossible, the possible and the real". Such a vision is central to any discussion on transdisciplinarity and has its roots in Scotist realism.

Up to this point I hope I have successfully argued first for the univocity of being without reliance upon transcendence (although not discounting transcendental experience such as awe), and, second that we best understand that transdisciplinarity provides a way of engaging within the univocity of the multiple realities of this world and that actions are the responsibility of oneself taking a stance on what one wills oneself to.

\subsection{Imagining not Mastering in a Transdisciplinary Scholastic Pedagogy}

The role of education seems evident; to know and then to become but became what? If we seek selfcultivation not only in the sense of a moral life but as a contented life, we need to will and develop potentials in oneself whilst amongst others. This may be achieved by balancing the internal and external causal forces of our self and our actions under self-volition, self-discipline and self-reflection. It is not deterministic for we are fallible, laced with ignorance, laziness and fears, and it requires capabilities, knowledges, and creativity in order that we might have the power to reflect and deliberate about the impact to be achieved by our action. It is through personal and collective reflections on the exploration of the relationship that our individual world views create deeper levels of collaboration but it must avoid a manifestation of a perceptive objectification. The idea of mastery over the external forces rather than a relationship with them as narratives of the transdisciplinary way to being, of being oneself. This mastery assume things can be mastered based on acceptance of the hegemony of logic and of causation which denies the emergence of thing from mundus imaginalis; things that could be, not things that are of fantasy, or imaginary. Such thinking is not about mastery over the object but a merging of the subject and the object in an oneness of mutual respect and dignity. This hiddenness is revealed through spiritual and secular ways but is never totally immanent or transcendental. Its singularity is triggered by the necessary difference of things yet within the connectivity of all things. This mastery over the natural is a possibility, for that can be willed in Scotus' model. Teaching will extend our place in the world rather than ownership of it.

Such understanding of the world in terms of immanence and transcendence is benefited from engagement with individuals within it and reflecting our commonality and difference. It does not require closed paradigms of knowledge-making and values, nor does it require a scientism which excels in answering questions that it sets itself to answer well and claiming omnipotence over rigour and solution. The creative will's conceptual is intrinsic to the scholastic approach to understanding which precedes experience, the emergence of causal powers and can shape one's place and agency in the world.

In developing transdisciplinary methodological inquiry the scholastic method of defining a problem clearly by collecting differing views, both within opposing views and between them, recognising differing ways of constructing arguments and giving them credence and collectively equating them on their own merits provides such a rigour based on conceptual rationality but without the proscribing disciplinary methods of action. The requirement is that prior to the intellectual decision, the moral agency of affactio 
iustitae should dominate. Such a pedagogy will recognise the freedom to choose for all, of openness to others and tolerance of their ideas. It would celebrate the sameness and the diversity between us and it will be able to embrace the univocity of our being both immanent and transcendental with other things in our universe.

The role of teaching is to help the will to harness the intellect to exist with others, to influence the world for the betterment of all whilst maintaining an identity of self-worth. In transdisciplinary terms, this is revealed within the concept of the univocity of Being in all things in order to develop abilities of individual self-observation, to be self-critical and to confront our illusions of who we might be and what we might become. It is about confronting self-deception when making truth statements achieved through self-referential truth seeking and finding strength to honour what one finds through such examination. For self-deception might be expedient to protect ourselves from pain but it can lead us from despair to dread and thwarts our courage to be.

This is risky, for in doing so the unpleasant and regrettable about oneself is revealed as well as the praiseworthy but it is inevitable if the logical analysis of the scholastics is followed rigorously. It is also enables us to appreciate universality and difference and to seek to reveals the co-existent transcendentals (goodness, truth, beauty and unity) in our being and Being. It would manifest itself in our world, respecting other entities through compassion.

This will call forth threefold transdisciplinary attitudes from the academic:

- First, to reveal the importance of the balance of particularity, singularity and commonality in shaping our being and enabling our flourishment in our becoming. This requires facing the paradox of the one and many in teaching that allows diverse voices to be heard without compromise to the group;

- Second, to show ways in which capabilities can be manifest in the presence of our being in the world with others and to realize, reflectively, the potential to develop ways of seeing and knowing that influence the ways all disciplines are taught. It seeks a shift, not a rupture, from a hegemonic discipline perspective to a plurality of world views; and

- Third, to harness students' desires to realize their capabilities which are neither delusionary nor closed in the complex and harsh plateaus of realities we exist in and where freedom of the will, individually and collectively is a condition of self-cultivation.

Such an approach would seek to encourage wonder, compassion, respect and curiosity in the things we notice within the ecology of Being and our part in it. This might lead to active, liberating, poetic and creative pedagogies of enquiry such as student-led play where collaboration and individuality are fused in a self-cultivation of being participants in, not observers of new realities. In the presence of these new realities a praxis for good and justice would frame the experience of education. As a process it would seek harmony between the intellect, feelings and body to remove the distinction between formal education and the civic engagement allowing self-cultivation to be taught in the sense of the joint forms of agency argued for by Nicolescu and Scotus. The actualization is manifest in multiple forms, shaping the patterning of our ways of becoming, and are implicitly linked to an educative appreciation of the willed self-cultivation of the individual whilst retaining a duty to others. Our individuality is the freedom with which we make choices as to our becoming in the flux of this unity.

The rationality that underpins the cultural logic of scholasticism can take place contemporarily (as it did in mediaeval times) at ${ }^{15}$ the frontier between learned and popular culture, between public and private spheres, between polemic and poetry, and between tragedy and comedy. It provides a structure for enquiry based on the metaphysical axioms of Nicolsecu's transdisciplinarity and contextualise in the complexity of living today where sources of knowledge are not closed set of texts and categories but a dialectic between immanence and transcendence, not absolute truths but as a pragmatic methodological to conceive of solution to complex problems.

\footnotetext{
${ }^{15}$ See Novikoff's [29] fully explanation for a historical context
} 


\section{Conclusion}

The transdisciplinary attitude emerges from this discussion as strongly as it does from Nicolescu's own work, and that is reassuring. The ideas developed here, however, are not dependent on an ontology of the physical world and put at the heart of the discussion notion of emergence, causal powers and a world not revealed through scientific methods but rather through the rational questioning of what is taken as truth. This approach seeks to contribute to the development of a transdisciplinary attitude through seeking to use it in developing a world view which has many applications. In so doing it promotes a disposition of compassion, wonder and awe which is at the heart, I believe, of the Nicolescu project.

Funding: This research received no external funding.

Conflicts of Interest: The authors declare no conflict of interest.

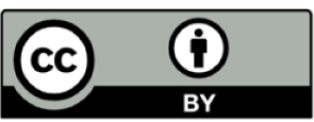

Copyright (C) 2021 by the authors. This is an open access article distributed under the Creative Commons Attribution License (https://creativecommons.org/licenses/by/4.0/), which permits unrestricted use, distribution, and reproduction in any medium, provided the original work is properly cited.

\section{References}

[1] de Freitas, L., E. Morin, and Nicolescu, B. (1994). The charter of transdisciplinarity (Trans. K.-C. Voss). http://ciret-transdisciplinarity.org/chart.php\#en. Accessed 12.9.2021.

[2] Nicolescu, B. (1985). Nous, la particule et le monde [We, the particle and the world]. Paris, France: Le Mail.

[3] McGregor, S. (2015). The Nicolescuian and Zurich Approaches to Transdisciplinarity, Integral Leadership Review, http://integralleadershipreview.com/13135-616-the-nicolescuian-and-zurich-approaches-totransdisciplinarity/ (accessed 30.8.2021.

[4] Feser, E. (2013). Scholastic Metaphysics a Contemporary Introduction. Transaction Books: Rutgers University, Ne Jersey.

[5] Scott, D. (2017). Interdisciplinarity, Transdisciplinarity and the Higher Education Curriculum. In: Gibbs P. (eds) Transdisciplinary Higher Education. Springer, Cham, 31-43.

[6] Aristotle (1984). De Amina, Metaphysics, Topic, Nicomachean Ethics in the Complete Works of Aristotle, (ed. J. Barnes) Princeton: Princeton University Press.

[7] Beere, J. (2009). Doing and Being: An interpretation of Aristotle's Metaphysics Theta. Oxford, Oxford University Press.

[8] Deleuze, G. (2014). Difference and Repetition, London: Bloomsbury.

[9] Wolter, A. B. (1997). Duns Scotus on the Will and Morality (Ed) by W A. Frank) Catholic University of America Pres.

[10] Cross . R. (1999). Duns Scotus, Oxford: Oxford University Press. Academic

[11] Bates, T. (2020). Duns Scotus and the Problem of Universals, London: Continuum International Publishing.

[12] Scotus J. D. (2005). Early Oxford Lecture on Individuation, A. B. Wolter (Trans) New York: Franciscan Institute Publications.

[13] Dumont, S. T. (2005). Duns Scotus's Parisian Question on the Formal Distinction, Vivarium. 43 (1), 7-62.

[14] Spinoza, B. (1992). Ethics, Treatise on the Emendation of the Intellect and selected Letters. (Trans), S. Shirley, Indianapolis: Hackett Pubhishing.

[15] Moore, A. W. (2015). The Presidential Address: Being, Univocity, and Logical Syntax Proceedings of the Aristotelian Society, 115, 1:1 1-23. 
Paul Gibbs

Scholasticism with a Transdisciplinary Attitude

[16] Corbin, H. (2014). Avicenna and the Visionary Recital, Prinston University Press, New York.

[17] Nicolescu, B. (2002). Manifesto of Transdisciplinarity, (Trans, K-c. Voss), New York: SUNY Press.

[18] Hoffmann, T. (1999). The distinction Between Nature and Will in duns Scotus, Archives d'histoire doctrinale et littéraire du Moyen Age,. 66 pp. 189-224.

[19] Normare, C. G. (2021). Powers. Possibilities, and Time: Notes for a Programme, in (Eds) Hill, B; Lagerlund, H. and Psillos, S. Reconsidering Causal Powers, Oxford: Oxford University Press.

[20] Almeder, R. (1973). Peirce's Pragmatism and Scotistic Realism Transactions of the Charles S. Peirce Society, 9: 1 pp. $3-23$.

[21] ] Garrison, J. (2005). Curriculum, Critical Common-sensism. Scholasticism and the Growth of Democratic Character, Studies in Philosophy and Education, 24: 179-211.

[22] Vos, A. (2009). The Philosophy of John Duns Scotus, Edinburgh: Edinburgh University Press.

[23] Van Asselt W. J. and Van Assel W. (2011). Introduction to Reformed Scholasticism (Reformed HistoricalTheological Studies), Kentwood,: Reformation Heritage Books.

[24] Peirce C. S. (1905). Issues of Pragmatism. The Monist, 15: 4 pp. 481-499.

[25] Rouwendal, P, L. (2001). The Method of the Schools: Medieval Scholasticism, in Van Asselt W. J. and Van Assel W. Introduction to Reformed Scholasticism (Reformed Historical-Theological Studies), Kentwood,: Reformation Heritage Books, 56-77.

[26] Vos, Jaczn; Veldhuis, Looman-Graaskamp. Dekker, D and den Bok, N. W. John Duns Scotus Contingency and Freedom Lectura I 39, Dordrecht: Kluwer Academic PublsihserA. H.

[27] Peirce C. S. (1892). The Doctrine of Necessity Examined. The Monist, 2: 3, pp. 321-337.

[28] wolterNovikoff, A. J. (2012). Toward a cultural history of scholastic disputation. The American Historical Review, 117:2,.330 -360.

\section{About the Author}

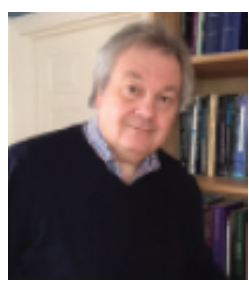

Dr. Paul Gibbs is Professor and Director of the Doctoral School, East European University. He is professor emeritus at Middlesex University, founder of the Centre for Education Research and Scholarship, and visiting professor at UTS Sydney and Azerbaijan university. His is a fellow of ATLAS as well as the Centre for Higher Education Policy, New College Oxford. He is an educator and researcher having taught notions of transdisciplinarity alongside social realism and Heideggerian hermeneutics. He has over 30 successful transdisciplinary professional doctorate students. He has published 20 books on topics ranging from the marketing of higher education to vocationalism and higher education and has published more than 100 academic articles. His particular approach to transdisciplinarity is informed by the works of Heidegger, Duns Scotus, and Deleuze and the theoretical insights of Basarab Nicolescu. He is also the series editor of SpringerBriefs on Key Thinkers in Education. 